\title{
Factors Associated with Tramadol Abuse: A Cross-Sectional Study Among Commercial Drivers and Assistants in the Accra Metropolitan Area of Ghana
}

\author{
Mavis Danso ${ }^{1,2} \cdot$ Francis Anto $^{1}$ (D) \\ Accepted: 9 April 2021 / Published online: 28 April 2021 \\ (c) The Author(s) 2021
}

\begin{abstract}
Background There is increasing public health concern regarding the addiction and dependence potential of tramadol. Objective This study sought to determine factors associated with tramadol abuse among commercial drivers and assistants in the Accra Metropolitan Area of Ghana.

Patients and Methods The study employed a mixed-method quantitative and qualitative approach. It involved a crosssectional survey and focus group discussions with commercial drivers and assistants at selected transport terminals in Accra. Data on abuse, reasons for abuse, sources of supply, and factors associated with abuse were collected from the respondents and analyzed using STATA and Nvivo, as appropriate.

Results Of the 458 study participants, 114 (24.9\%) indicated that they abused tramadol. The mean ( \pm standard deviation) age of those who abused tramadol ( $25.14 \pm 5.87$ years) was significantly lower than that of nonabusers $(28.23 \pm 9.6$ years), $t(456)=-3.60 ; p=0.001$. The level of risk of dependence on tramadol among the abusers was high, as $49.1 \%(56 / 114)$ of abusers were estimated to have a composite risk score of $\geq 27$. Various socioenvironmental factors, including tension or fighting among family members (adjusted odds ratio [AOR] 7.73; 95\% confidence interval [CI] 3.33-17.98; $p<0.001$ ), abuse of drugs by a family member (AOR 2.27 ; 95\% CI 1.26-4.11; $p=0.007$ ), and having a friend who abused drugs (AOR $2.17 ; 95 \%$ CI 1.22-3.89; $p=0.009$ ) were associated with tramadol abuse. Reasons given for using tramadol included pain relief and sexual enhancement.

Conclusion The level of tramadol abuse and dependence was high. This calls for interventional programs, including health education, as dependency on tramadol has dire consequences on productivity.
\end{abstract}

Francis Anto

fanto@ug.edu.gh

Mavis Danso

mavis.danso@fda.gov.gh

1 School of Public Health, University of Ghana, Legon, Accra, Ghana

2 Food and Drugs Authority, Accra, Ghana

\section{Key Points}

A high proportion (24.9\%) of commercial drivers and assistants in the Accra metropolis of Ghana abuse tramadol.

In total, $50 \%$ of the commercial drivers and assistants who abused tramadol needed the drug to be able to carry out their daily activities effectively.

Urgent and effective public health action, including health education, is required to help reduce the incidence of tramadol abuse in Accra, Ghana. 


\section{Introduction}

Globally, the use and abuse of prescription and controlled medicines is increasing, though the type of substance abused may differ from country to country $[1,2]$. The nonmedical use of pharmaceutical opioids such as tramadol is a fast-emerging public health problem leading to increasing calls for scheduling amendments to existing policies, surveillance, research, and health promotion measures [3].

Tramadol was previously perceived to have a lower side-effect profile than other opioids and a relatively lower dependency level than morphine [4-7] and oxycodone [2]. This, together with its relative cheapness, availability, and accessibility, resulted in widespread use and abuse. However, it is now clear that prolonged use and higher than recommended daily doses can result in dependency [2].

Concerns have been raised in the African region about the upsurge of the abuse of tramadol, a drug that is not internationally controlled, especially in North and West Africa. In 2015 alone, the Republic of Benin seized over 40 million fraudulent tramadol tablets [8]. Increased abuse of tramadol has been observed in the Sahel region and Libya, which is considered the source of tramadol trafficked to Egypt. In 2015, Jordan seized about 142,000 ampoules of tramadol, and 1 million tramadol pills originating from India were also seized in 2016 at Imam Khomeini International Airport in Tehran [8]. The African region has reported large quantities of seized tramadol, accounting for $87 \%$ of the world's seizure of pharmaceutical opioids in 2016 alone [1]. The widespread abuse of opioids may be linked to its availability, accessibility, and affordability [9].

Investigations across all the administrative regions of Ghana by the Food and Drugs Authority, Ghana (FDA) in 2016, 2017, and 2018 confirmed the abuse of tramadol by some youth, students, market women, commercial drivers, and assistants, popularly known as driver's mates. Tramadol found on the market had strengths of 120, 200, and 250 $\mathrm{mg}$, all higher than the registered strengths of $37.5,50$, and $100 \mathrm{mg}$ tablets/capsules in Ghana [1].

Concerns are being raised about the long-term and high-dose use of tramadol because of its many effects, including addiction, dependence, seizures, hallucination, confusion, respiratory depression, and liver and kidney disease [4, 10-13].

The abuse of prescription medicines such as tramadol leads to increased morbidity and mortality, and increases the financial burden of indirect costs for health care, health promotion, surveillance, and reduced economic productivity [14]. Rehabilitation and treatment of problematic drug users is of utmost importance, but most countries in the African region have inadequate facilities and infrastructure to facilitate such rehabilitation and treatment.
The rate of vehicular accidents and associated injuries and deaths on roads in Ghana has recently increased [15, 16]. Studies have established that some road accidents are due to substance abuse by drivers [17, 18]. Driving under the influence of drugs can pose a threat not only to the driver but also to passengers and pedestrians. The current study was therefore undertaken to determine the prevalence of, level of dependence on, and factors associated with the abuse of tramadol among commercial drivers and assistants in the Accra Metropolitan Area (AMA) of Ghana to aid in the design of appropriate interventions to curb its illicit use.

\section{Materials and Methods}

\subsection{Study Area}

The study was conducted in the AMA of the Greater Accra region of Ghana. The AMA has a total surface area of $139.671 \mathrm{~km}^{2}$ and an estimated population of 1,665,086 [19]. The city is bounded to the West by the Ga South Municipality, to the east by La Dadekotopon Municipality, to the North by Ga West Municipality, and to the South by the Gulf of Guinea. The AMA has six submetropolises: Ablekuma Central, Ablekuma South, Ashiedu Keteke, Ayawaso Central, Okai Koi South, and Osu Klotey. The city is the economic hub of the greater Accra region and houses a number of financial institutions, manufacturing industries, health institutions, oil companies, telecommunication companies, large transport terminals, and education, tourism, and other important establishments. The existence of these institutions attracts people from all parts of the country and beyond for various business transactions, and their movement significantly depends on commercial transportation. Approximately 106 transport terminals exist in the AMA [19].

\subsection{Study Design}

A cross-sectional analytic study was conducted among commercial drivers and assistants at six randomly selected transport terminals in the AMA of Ghana in June 2019 using a mixed-methods approach. Data on abuse of tramadol and associated factors were collected from respondents using a pretested structured questionnaire. A focus group discussion (FGD) was also held at one of the selected transport terminals among some drivers and assistants (three drivers and three assistants, but not drivers and assistants of the same vehicle). This was to explore their experiences of and views on the abuse of tramadol by drivers and assistants. The participants were purposively selected from among those who were not loading passengers immediately and so had some time to spare for the discussion. 


\subsection{Sample Size Estimation and Sampling}

A minimum sample size of 384 was estimated using the Cochrane formula, $n=\left(Z^{2} p q\right) / d^{2}$ [20], where $n$ is sample size, $Z$ is the $z$-score that corresponds with the $95 \%$ confidence interval $(\mathrm{CI} ; 1.96), p$ is the assumed proportion of commercial drivers who abuse tramadol $(50 \%,=$ $0.50), q=1-p(1-0.50=0.50)$, and $d$ is the margin of error, set at $5 \%(0.05)$. Assuming a nonresponse rate of $10 \%$, a sample of 423 was deemed appropriate to estimate the prevalence of tramadol abuse and associated factors among commercial drivers and assistants in Accra. No data on the abuse of tramadol among commercial drivers are available, so we assumed that $50 \%$ abuse the drug. This assumption also provides a larger sample size for the required subanalysis.

One transport terminal was randomly selected from each of the six submetropolises of the study area. This was done by writing the names of all transport terminals in each submetropolis on pieces of paper, which were then folded and placed in a container that was well shaken to mix the pieces of paper. One transport terminal was picked per submetropolis to represent the submetropolis. The selected transport terminals were Kaneshie market station, Dansoman last stop, Tema station, Cocoa Marketing Board station, Circle Odawna station, and the Lapaz N1 station. The sample size was equally distributed among the six transport terminals as the managers could not tell how many active vehicles would be in operation at the time.

At the selected transport terminals, drivers and assistants were enrolled into the study using a simple random sampling procedure. The registration numbers of the vehicles on the scale board for loading of passengers at the time of data collection were written on pieces of paper that were then folded, put into a container, and mixed very well. Either a driver or an assistant at the terminal was invited to pick a number at a time until the required sample size for the particular terminal was obtained. Drivers or assistants whose car numbers were selected were enrolled into the study after providing informed consent. Those who declined to participate in the study were replaced, and those who had to load passengers because it was their turn were also replaced. The data collection took place from 0800 to $1700 \mathrm{~h}$ each day at any particular terminal.

One FGD consisting of six participants conveniently selected participated in the qualitative part of the study. This was to explore the views of participants on the use of the drug among commercial drivers and assistants in the metropolis. One of the six terminals was selected by simple random sampling for the FGD. Participants in the FGD were not part of the quantitative part of the study.

\subsection{Data Collection Tools and Procedures}

\subsubsection{Quantitative Data Collection}

A structured pretested questionnaire was administered to the drivers and assistants sampled at the various transport terminals. The questionnaire was developed specifically for this study and guided by Open Data Kit software [21]. The questionnaire had three sections: the first covered the demographic characteristics of the respondent, the second covered general drug use, and the third covered tramadol abuse and factors likely to influence its abuse (a person was considered a tramadol abuser if they had ever used the drug without prescription and/or ever used a dosage $\geq 100 \mathrm{mg}$ ). Tramadol use dependence was assessed using the World Health Organization (WHO) Alcohol, Smoking and Substance Involvement Screening Test (ASSIST) tool [22]. The data collection for each respondent lasted 10-15 min and was completed before their turn to load passengers.

\subsubsection{Qualitative Data Collection}

One FGD consisting of a panel of six (three drivers and three assistants from different vehicles) was conducted at one of the six terminals (Tema station) to gain some insight into the experiences and views of drivers and assistants on tramadol abuse among the group. The discussion took place in the station master's office and was facilitated using an interview guide with coded themes. Information on the abuse and availability of tramadol, sources of supply, and factors associated with abuse were solicited from the discussants. An audio recorder was used to record all discussions, and one trained research assistant took notes. The interview lasted for 20-30 min.

\subsection{Quality Control}

The questionnaire was pretested on 20 people (ten drivers and ten assistants) at the Madina main transport terminal. The research assistants were trained over a period of 2 days on data collection and how to seek consent. The research assistants were supervised, and collected data were reviewed daily to ensure accuracy and completeness.

\subsection{Data Processing and Analysis}

Data collected were extracted from the Open Data Kit software into Microsoft Excel, checked for completeness and accuracy, and imported to STATA version 15 for cleaning and analysis. Descriptive analysis was carried out for the background characteristics of respondents and summarized as frequencies, percentages, means, standard deviations, and medians. 
We used chi-squared/Fischer's exact tests to establish associations between tramadol abuse and the set of independent variables. Any association with a $p$ value $<0.05$ was considered statistically significant. Logistic regression analysis reporting odds ratios was used to determine the strength of the association between tramadol abuse and any significant independent variable that was found after the chisquared test.

Tramadol dependence among users was assessed using the WHO ASSIST tool. The composite score of respondents was categorized into three levels, with a score of 0-3 indicating low risk, a score of 4-26 indicating moderate risk, and a score $\geq 27$ indicating high risk [22].

Recordings of the FGD were transcribed, validated using the notes that were taken, and analyzed thematically. The framework of the thematic analyses was done using the approach espoused by Braun and Clarke [23]. This involved six procedures: familiarization with the data, initial coding of the data, searching for themes, reviewing themes, defining and renaming of themes, and writing of the report. The analysis was done using Nvivo v.11.

\section{Results}

\subsection{Demographic Characteristics of Study Participants}

In total, 514 commercial drivers $(n=254)$ and assistants ( $n=260)$ were invited to participate in the study; of these, 458 (228 drivers; 230 assistants) agreed, giving a response rate of $89.11 \%$. Participants were all male and were aged 18-66 years (median 21; interquartile range [IQR] 19-23); most were single $(n=307$ [67.03\%]), and commercial driving was the sole occupation for $75.11 \%$. Most of the drivers and assistants had formal education (95.2\%), with $48.91 \%$ to secondary and higher levels (Table 1). They worked long hours (median 13; IQR 12-14) on a daily basis for a monthly average income of 500 Ghana cedis $(\mathrm{GH} \phi)$ (range 250-800), approximately \$US85 (range 42.5-136).
Table 1 Background characteristics of study participants and tramadol abuse

\begin{tabular}{|c|c|c|c|c|c|}
\hline \multirow[t]{2}{*}{ Variable } & \multirow[t]{2}{*}{ Frequency } & \multicolumn{2}{|c|}{ Tramadol abuse } & \multirow[t]{2}{*}{$\chi^{2}$} & \multirow[t]{2}{*}{$\mathrm{p}$-Value } \\
\hline & & Yes & No & & \\
\hline \multicolumn{6}{|l|}{ Age group, years } \\
\hline$<20$ & $98(21.4)$ & $23(23.47)$ & $75(76.53)$ & 15.04 & 0.002 \\
\hline $21-30$ & $241(52.62)$ & $74(30.71)$ & 167 (69.29) & & \\
\hline $31-40$ & $76(16.59)$ & $15(19.74)$ & $61(80.26)$ & & \\
\hline $41-50$ & $29(6.33)$ & $1(3.45)$ & $28(96.55)$ & & \\
\hline$\geq 51$ & $14(3.06)$ & $1(7.14)$ & $13(92.86)$ & & \\
\hline \multicolumn{6}{|l|}{ Occupation } \\
\hline Driver & $228(49.78)$ & $47(20.61)$ & $181(79.39)$ & 4.44 & $<0.001$ \\
\hline Assistants & $230(50.22)$ & $67(29.13)$ & $163(70.87)$ & & \\
\hline \multicolumn{6}{|l|}{ Religious affiliation } \\
\hline Christian & $390(85.15)$ & $95(24.36)$ & $295(75.64)$ & 9.2 & 0.027 \\
\hline Muslim & $41(8.95)$ & $7(17.07)$ & $34(82.93)$ & & \\
\hline Other(s) & $27(5.9)$ & $12(44.44)$ & $15(55.56)$ & & \\
\hline \multicolumn{6}{|l|}{ Marital status } \\
\hline Single & 307 (67.03) & $90(29.32)$ & $217(70.68)$ & 23.92 & $<0.001$ \\
\hline Married & $120(26.2)$ & $12(10)$ & $108(90)$ & & \\
\hline Divorced & $12(2.62)$ & $3(25)$ & $9(75)$ & & \\
\hline Cohabit & $19(4.15)$ & $9(47.37)$ & $10(52.63)$ & & \\
\hline \multicolumn{6}{|l|}{ Additional work } \\
\hline Had additional work & $114(24.89)$ & $34(29.82)$ & $80(70.18)$ & 1.98 & 0.16 \\
\hline No additional work & $344(75.11)$ & $80(23.26)$ & $264(76.74)$ & & \\
\hline \multicolumn{6}{|l|}{ Level of education } \\
\hline Never attended school & $22(4.8)$ & $4(18.18)$ & $18(81.82)$ & 1.71 & 0.64 \\
\hline Primary & $212(46.29)$ & $51(24.06)$ & $161(75.94)$ & & \\
\hline Secondary or higher & $224(48.91)$ & $59(26.34)$ & $165(73.66)$ & & \\
\hline
\end{tabular}

Data are presented as $n(\%)$ unless otherwise indicated 


\subsection{Tramadol Abuse and Dependence Among Study Participants}

Of the 458 respondents, 114 (24.9\%) indicated that they used tramadol. Users were spread among all the age groups, but the highest proportion was among those aged 21-30 years. The mean age of those who abused tramadol (25.14 \pm 5.87 years) was significantly lower than that of nonabusers (28.23 \pm 9.6 years), $t(456)=-3.60, p=0.001$ (Table 1 ). A significantly higher proportion of assistants than drivers also reported using the $\operatorname{drug}\left(\chi^{2}=4.44, p<0.001\right)$. The level of risk of dependence on tramadol among the abusers was high, as $49.12 \%(56 / 114)$ were estimated to have a composite risk score of $\geq 27$ (Fig. 1).

\subsection{Relationship Between Socioecological and Sociodemographic Factors and Tramadol Abuse}

Several socioecological factors, including not being brought up by their parents $\left(\chi^{2}=21.29, p<0.001\right)$, parents not being strict on them during their childhood $\left(\chi^{2}=11.26, p=0.01\right)$, having family members who sometimes fought among themselves $\left(\chi^{2}=64.64, p<0.001\right)$, and some family members using drugs $\left(\chi^{2}=37.66, p<0.001\right)$, were associated with tramadol abuse among the study participants (Table 2). Some sociodemographic factors were also associated with abuse of tramadol, including age $\left(\chi^{2}=15.04, p=0.002\right)$ and marital status $\left(\chi^{2}=22.58, p<0.001\right)$. Participants who were married were $27 \%$ less likely to abuse tramadol than those who were single. Similarly, participants who had worked for $\geq 21$ years were $12 \%$ less likely to abuse tramadol than those who had worked for $\leq 5$ years (unadjusted odds ratio [UOR] 0.1; 95\% CI 0.02-0.88). However, after adjusting for confounding factors, age, marital status, and occupation were not statistically associated with the abuse of tramadol (Table 3). Factors that were significantly associated with the abuse of the drug were supervision by parents during childhood, fighting among family members, and a family member or a friend being an abuser of drugs. Participants whose parents were very strict on them during childhood were $33 \%$ less likely to abuse tramadol than those whose parents were unconcerned (95\% CI 0.12-0.92). Similarly, participants who had a family member (adjusted odds ratio [AOR] 2.27; 95\% CI 1.26-4.11) or a friend (AOR 2.17; 95\% CI 1.22-3.89) who abused drugs were more likely to abuse tramadol (Table 4).

\subsection{Association Between Other Substances of Abuse and Tramadol Abuse}

Results from the multiple logistic regression analysis controlling for demographic and socioenvironmental factors showed that four of the six factors on the abuse of other substances of abuse were statistically significant in predicting tramadol abuse among the respondents (Table 5). These drugs were alcohol, tobacco, marijuana, and heroin. Participants who consumed alcohol were 4.74 times more likely to abuse tramadol than those who did not consume alcohol (95\% CI 2.64-8.50). Similarly, participants who used tobacco were more likely to abuse tramadol (AOR 3.18; 95\% CI 1.51-6.71) than those who did not use tobacco. Those who used marijuana (AOR 4.17; $95 \% \mathrm{CI}$

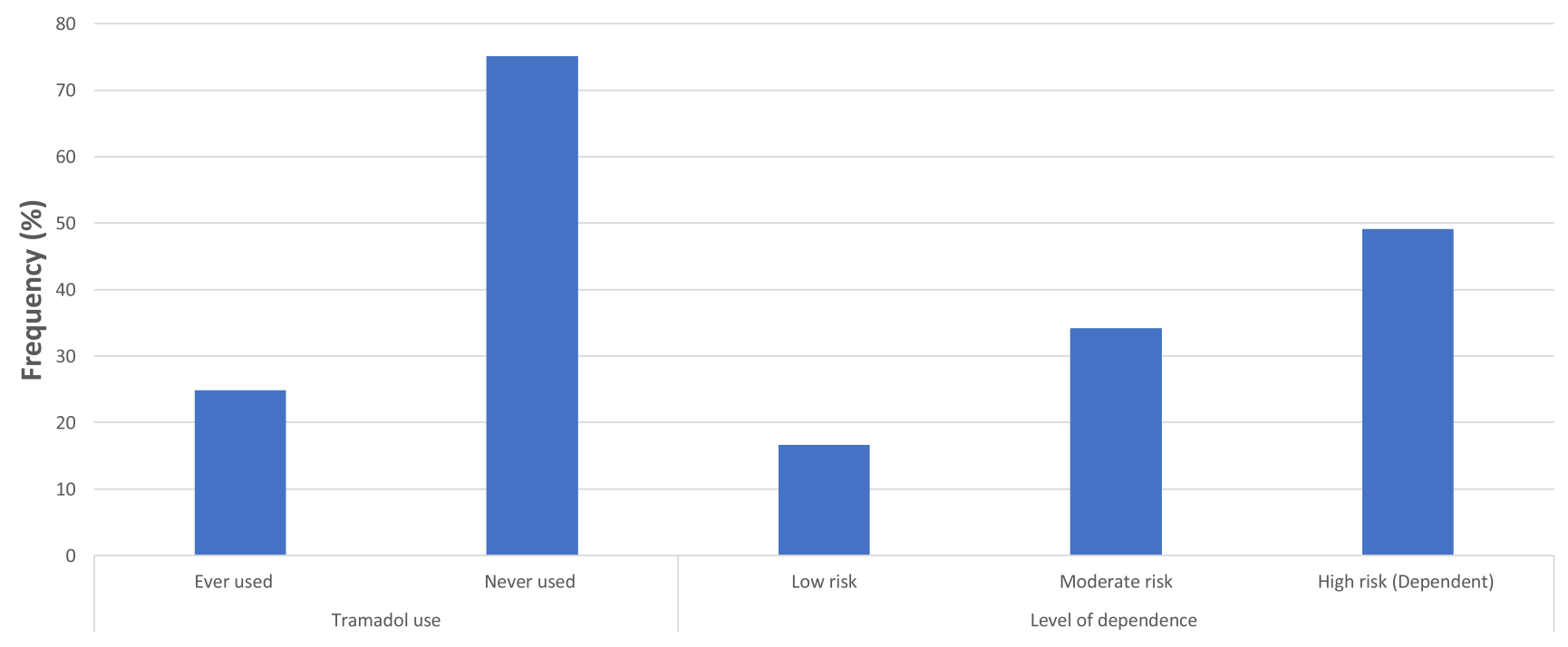

Abuse and risk of dependence

Fig. 1 Abuse of tramadol and level of risk of dependence among commercial drivers and assistants 
Table 2 Socioenvironmental factors and tramadol abuse

\begin{tabular}{|c|c|c|c|c|c|}
\hline \multirow[t]{2}{*}{ Variables } & \multirow[t]{2}{*}{ Frequency } & \multicolumn{2}{|c|}{ Tramadol abuse } & \multirow[t]{2}{*}{$\chi^{2}$} & \multirow[t]{2}{*}{ p-Value } \\
\hline & & Yes & No & & \\
\hline \multicolumn{6}{|l|}{ Living with parents/guardian } \\
\hline Did not live with parents/guardian & $273(59.61)$ & $67(36.22)$ & $118(63.78)$ & \multirow[t]{2}{*}{21.29} & \multirow[t]{2}{*}{$<0.001$} \\
\hline Lived with parents/guardian & 185 (40.39) & $47(17.22)$ & $226(82.78)$ & & \\
\hline \multicolumn{6}{|l|}{ Parents together when growing } \\
\hline Parents not together & $126(27.51)$ & $88(26.51)$ & $244(73.49)$ & \multirow[t]{2}{*}{1.68} & \multirow[t]{2}{*}{0.194} \\
\hline Parents together & $332(72.49)$ & $26(20.63)$ & $100(79.37)$ & & \\
\hline \multicolumn{6}{|l|}{ Supervision of parents or guardians } \\
\hline Liberal/unconcerned & $69(15.07)$ & $27(39.13)$ & $42(60.87)$ & \multirow[t]{4}{*}{11.26} & \multirow[t]{4}{*}{0.01} \\
\hline Moderate & $213(46.51)$ & $53(24.88)$ & $160(75.12)$ & & \\
\hline Strict & $11(24.24)$ & $24(21.62)$ & $87(78.38)$ & & \\
\hline Very strict & 65 (14.19) & $10(15.38)$ & $55(84.62)$ & & \\
\hline \multicolumn{6}{|l|}{ Current residence } \\
\hline Own house & $67(14.63)$ & $21(31.34)$ & $46(68.66)$ & \multirow[t]{5}{*}{4.88} & \multirow[t]{5}{*}{0.3} \\
\hline Family house & 99 (21.62) & $24(24.24)$ & 75 (75.76) & & \\
\hline Rented house & $200(43.67)$ & $43(21.5)$ & $157(78.5)$ & & \\
\hline Friend's house & $51(11.14)$ & $17(33.33)$ & $34(66.67)$ & & \\
\hline Other & $41(8.95)$ & $9(21.95)$ & $32(78.05)$ & & \\
\hline \multicolumn{6}{|l|}{ Tension/fight in the family } \\
\hline Never & $129(27.95)$ & $10(7.81)$ & $118(92.19)$ & \multirow[t]{4}{*}{64.64} & \multirow[t]{4}{*}{$<0.001$} \\
\hline Rarely & $169(36.90)$ & $32(18.93)$ & $137(81.07)$ & & \\
\hline Sometimes & $147(32.10)$ & $70(47.62)$ & $77(52.38)$ & & \\
\hline Always & $14(3.06)$ & $2(14.29)$ & $12(85.71)$ & & \\
\hline \multicolumn{6}{|c|}{ Family member using drugs when growing up } \\
\hline Not using drugs & $269(58.73)$ & $75(39.68)$ & $114(60.32)$ & \multirow[t]{2}{*}{37.66} & \multirow[t]{2}{*}{$<0.001$} \\
\hline Using drugs & $189(41.27)$ & $39(14.5)$ & $230(85.5)$ & & \\
\hline \multicolumn{6}{|c|}{ Close friend using drugs when growing up } \\
\hline Not using drugs & $241(52.62)$ & $80(36.87)$ & $137(63.13)$ & \multirow[t]{2}{*}{31.64} & \multirow[t]{2}{*}{$<0.001$} \\
\hline Using drugs & 217 (47.38) & $34(14.11)$ & 207 (85.89) & & \\
\hline
\end{tabular}

Data are presented as $n(\%)$ unless otherwise indicated
$0.2-1.55)$ were also more likely to abuse tramadol than those who did not (Table 5).

\subsection{Focus Group Discussion}

\subsubsection{Abuse of Tramadol}

The participants in the FGD confirmed that some drivers and assistants abused tramadol, which they usually acquired from "ghettos," and that it came in different strengths:

"Some drivers take tramadol while their assistants do not take, others too their assistants do take while the drivers do not take tramadol." (Participant \#6; driver). "The tramadol is 225 , the blue is the 120 , and we also have 150 , which is the aphrodisiac and the 120 is the D-10." (Participant \#4; driver).

\subsubsection{Reasons for Abuse of Tramadol}

The discussants indicated that the drivers and assistants used tramadol for various reasons, including to relieve stress and pain, to boost energy, and to enhance sexual activity:

"The reason I take tramadol is to relieve body pains associated with driving and after taking it, I am able to do everything without pains" (Participant \#4; driver). "When you take tramadol, it prolongs sexual intercourse because if you use your normal strength, ladies of today are not appreciative, but when you take tramadol, the lady will even sing your praises." (Participant \#2; bus attendant).

\subsubsection{Factors that Influence Tramadol Abuse}

Some participants shared their views on factors that influenced tramadol abuse, including lack of parental control 
Table 3 Association between demographic factors, socioenvironmental factors, and tramadol abuse

\begin{tabular}{|c|c|c|c|c|c|c|}
\hline \multirow[t]{2}{*}{ Variable } & \multicolumn{2}{|l|}{ Crude } & \multirow[t]{2}{*}{$p$ value } & \multicolumn{2}{|c|}{ Adjusted } & \multirow[t]{2}{*}{$p$ value } \\
\hline & OR & CI & & OR & CI & \\
\hline Age & 0.95 & $0.93-0.98$ & 0.002 & 1.04 & $0.97-1.12$ & 0.225 \\
\hline \multicolumn{7}{|l|}{ Religious affiliation } \\
\hline Christian & 1.00 & Reference & & 1.00 & Reference & \\
\hline Muslim & 0.64 & $0.27-1.49$ & 0.3 & 0.44 & $0.14-1.38$ & 0.160 \\
\hline Other & 2.48 & $1.12-5.49$ & 0.025 & 1.08 & $0.39-2.98$ & 0.878 \\
\hline \multicolumn{7}{|l|}{ Marital status } \\
\hline Single & 1.00 & Reference & & 1.00 & Reference & \\
\hline Married & 0.27 & $0.14-0.51$ & $<0.001$ & 0.45 & $0.18-1.13$ & 0.089 \\
\hline Divorced & 0.8 & $0.21-3.04$ & 0.747 & 0.49 & $0.94-2.51$ & 0.389 \\
\hline Cohabiting & 2.17 & $0.85-5.52$ & 0.104 & 1.89 & $0.58-6.12$ & 0.287 \\
\hline \multicolumn{7}{|l|}{ Educational level } \\
\hline No formal education & 1.00 & Reference & & 1.00 & Reference & \\
\hline Basic school & 1.43 & $0.46-4.41$ & 0.538 & 0.47 & $0.13-1.70$ & 0.248 \\
\hline Secondary and higher & 1.61 & $0.52-4.95$ & 0.407 & 0.44 & $0.12-1.59$ & 0.209 \\
\hline \multicolumn{7}{|l|}{ Occupation } \\
\hline Driver & 1.00 & Reference & & 1.00 & Reference & \\
\hline Driver mate & 1.58 & $1.03-2.43$ & 0.036 & 1.15 & $0.62-2.13$ & 0.658 \\
\hline Average income & 0.999 & $0.998-0.999$ & 0.002 & 0.999 & $0.998-1.00$ & 0.143 \\
\hline \multicolumn{7}{|l|}{ Years of working } \\
\hline$<5$ & 1.00 & Reference & & 1.00 & Reference & \\
\hline $6-10$ & 0.65 & $0.34-1.25$ & 0.199 & 0.88 & $0.37-2.11$ & 0.772 \\
\hline $11-15$ & 0.23 & $0.05-1.02$ & 0.052 & 0.29 & $0.04-2.05$ & 0.213 \\
\hline $16-20$ & 0.37 & $0.11-1.27$ & 0.113 & 0.23 & $0.04-1.19$ & 0.080 \\
\hline$\geq 21$ & 0.12 & $0.02-0.88$ & 0.037 & 0.13 & $0.01-2.11$ & 0.154 \\
\hline Daily working hours & 0.94 & $0.86-1.04$ & 0.227 & 1.03 & $0.90-1.18$ & 0.642 \\
\hline \multicolumn{7}{|l|}{ Additional work } \\
\hline No additional work & 1.00 & Reference & & 1.00 & Reference & \\
\hline Had additional work & 1.4 & $0.87-2.25$ & 0.161 & 1.46 & $0.79-2.70$ & 0.225 \\
\hline
\end{tabular}

$C I$ confidence interval, $O R$ odds ratio and peer influence. They agreed that most people who abused tramadol were introduced to it by their friends or colleagues at the transport terminals:

"Some people join groups that abuse drugs since they are homeless due to the absence of parents or guardians." (Participant \#5; bus attendant).

"It is the peer influence, because their friends are using tramadol, they also indulge in it." (Participant \#2; bus attendant).

A factor that particularly encourages the abuse of tramadol is its availability; it can also be an alternative source of extra income for some drivers and assistants. Some of the drivers and their assistants sold tramadol at some stations, just as peddlers at the various transport terminals.

"The drivers and their mates also peddle tramadol, I for instance, one of my masters (driver) sells some. It is a lucrative business; he can sell and make GH $₫ 50$ profit just in a day." (Participant \#1; driver).

Some participants agreed that economic factors influenced the abuse of tramadol. The need to work to earn an income to take care of oneself or the family can lead to abuse of some of these drugs as energy enhancers:

"Some learn it from friends, others too due to the circumstance they find themselves [in], there may be jobs one cannot do, but because of financial situations, the person will still have to do the job, raise money, and fend for himself, thereby abusing tramadol, so that he will not feel the stress of the job." (Participant \#6; driver). 
Table 4 Associations between demographic factors, socioenvironmental factors, and tramadol abuse

\begin{tabular}{|c|c|c|c|c|c|c|}
\hline \multirow[t]{2}{*}{ Variable } & \multicolumn{2}{|l|}{ Crude } & \multirow[t]{2}{*}{$p$ value } & \multicolumn{2}{|c|}{ Adjusted } & \multirow[t]{2}{*}{$p$ value } \\
\hline & OR & $95 \% \mathrm{CI}$ & & OR & $95 \% \mathrm{CI}$ & \\
\hline \multicolumn{7}{|l|}{ Living with parents/guardian } \\
\hline Did not live with parents/guardian & 1.00 & Reference & & 1.00 & Reference & \\
\hline Lived with parents/guardian & 2.73 & $1.77-4.22$ & $<0.001$ & 1.45 & $0.76-2.77$ & 0.264 \\
\hline \multicolumn{7}{|l|}{ Parents together when growing } \\
\hline Parents not together & 1.00 & Reference & & 1.00 & Reference & \\
\hline Parents together & 1.39 & $0.85-2.28$ & 0.196 & 1.60 & $0.84-3.05$ & 0.151 \\
\hline \multicolumn{7}{|l|}{ Supervision by parents or guardians } \\
\hline Liberal/unconcerned & 1.00 & Reference & & 1.00 & Reference & \\
\hline Moderate & 0.52 & $0.29-0.92$ & 0.024 & 0.56 & $0.26-1.89$ & 0.130 \\
\hline Strict & 0.43 & $0.22-0.83$ & 0.012 & 0.68 & $0.29-1.61$ & 0.381 \\
\hline Very strict & 0.28 & $0.12-0.65$ & 0.003 & 0.33 & $0.12-0.92$ & 0.034 \\
\hline \multicolumn{7}{|l|}{ Place resided when growing up } \\
\hline Urban & 1.00 & Reference & & 1.00 & Reference & \\
\hline Rural & 0.92 & $0.6-1.41$ & 0.708 & 1.39 & $0.78-2.49$ & 0.264 \\
\hline \multicolumn{7}{|l|}{ Current residence } \\
\hline Own house & 1.00 & Reference & & 1.00 & Reference & \\
\hline Family house & 0.7 & $0.35-1.4$ & 0.314 & 1.13 & $0.47-2.73$ & 0.790 \\
\hline Rented house & 0.6 & $0.32-1.11$ & 0.104 & 1.22 & $0.52-2.86$ & 0.650 \\
\hline Friend's house & 1.1 & $0.5-2.38$ & 0.819 & 1.27 & $0.44-3.63$ & 0.661 \\
\hline Other & 0.62 & $0.25-1.52$ & 0.292 & 0.78 & $0.24-2.53$ & 0.674 \\
\hline \multicolumn{7}{|l|}{ Tension/fight in the family } \\
\hline Never & 1.00 & Reference & & 1.00 & Reference & \\
\hline Rarely & 2.76 & $1.3-5.84$ & 0.008 & 2.56 & $1.11-5.89$ & 0.027 \\
\hline Sometimes & 10.73 & $5.21-22.09$ & $<0.001$ & 7.73 & $3.33-17.98$ & $<0.001$ \\
\hline Always & 1.97 & $0.39-10.04$ & 0.416 & 0.77 & $0.13-4.51$ & 0.770 \\
\hline \multicolumn{7}{|c|}{ Family member using drugs when growing up } \\
\hline Not using drugs & 1.00 & Reference & & 1.00 & Reference & \\
\hline Using drugs & 3.88 & $2.48-6.07$ & $<0.001$ & 2.27 & $1.26-4.11$ & 0.007 \\
\hline \multicolumn{7}{|c|}{ Close friend using drugs when growing up } \\
\hline Not using drugs & 1.00 & Reference & & 1.00 & Reference & \\
\hline Using drugs & 3.56 & $2.25-5.61$ & $<0.001$ & 2.17 & $1.22-3.89$ & 0.009 \\
\hline
\end{tabular}

$C I$ confidence interval, $O R$ odds ratio

\section{Discussion}

Most preclinical studies suggest that tramadol has potential for abuse, although the tendency is much lower than that of typical opioids $[2,24]$. This study employed both quantitative and qualitative research approaches to identify factors that may be influencing the abuse of tramadol amongst drivers and assistants in AMA, Ghana.

The prevalence of tramadol abuse among commercial drivers and assistants was $24.9 \%$. This was supported by findings from the FGD that some drivers and assistants are users of tramadol. This observation is quite worrying considering the harmful effect of the drug on the abuser, as tramadol abuse is known to cause hallucinations and confusion [25]. As such, increased access to this opioid analgesic by drivers and assistants can contribute to road accidents.
The level of tramadol abuse found in the current study is very high compared with findings by Bashirian et al. [26], who reported a prevalence of $12.5 \%$ amongst college students in Iran. Another study in Sweden analyzed hair samples and reported a higher prevalence of 33\% [27]. These different prevalences may be attributable to the methodologies of assessment, as the Swedish study used a more objective method. In a drug abuse study among commercial drivers in Nigeria, $19.4 \%$ of those who abused drugs in general (81.1\%) also abused tramadol [28].

Socioenvironmental factors that were associated with tramadol abuse included fighting or tension in the family, use of drugs by a family member or friend, and supervision by parents or guardians during childhood. It is welldocumented that parental supervision and control during adolescence is very important and has a protective effect 
Table 5 Association between other substances of abuse and tramadol abuse

\begin{tabular}{|c|c|c|c|c|c|c|}
\hline \multirow[t]{2}{*}{ Variable } & \multicolumn{3}{|l|}{ Crude } & \multicolumn{3}{|c|}{ Adjusted } \\
\hline & OR & $95 \% \mathrm{CI}$ & $p$ value & OR & $95 \% \mathrm{CI}$ & $p$ value \\
\hline \multicolumn{7}{|l|}{ Use of alcohol } \\
\hline Do not use alcohol & 1.00 & Reference & & 1.00 & Reference & \\
\hline Use alcohol & 7.57 & $4.67-12.27$ & $<0.001$ & 4.74 & $2.64-8.50$ & $<0.001$ \\
\hline \multicolumn{7}{|l|}{ Use of tobacco products } \\
\hline Not using tobacco products & 1.00 & Reference & & 1.00 & Reference & \\
\hline Use tobacco products & 7.1 & $3.93-12.84$ & $<0.001$ & 3.18 & $1.51-6.71$ & 0.002 \\
\hline \multicolumn{7}{|l|}{ Use of marijuana } \\
\hline Not using marijuana & 1.00 & Reference & & 1.00 & Reference & \\
\hline Using marijuana & 21.89 & $12.11-39.59$ & $<0.001$ & 4.17 & $0.2-1.55$ & $<0.001$ \\
\hline \multicolumn{7}{|l|}{ Use of cocaine/crack } \\
\hline Not using cocaine/crack & 1.00 & Reference & & 1.00 & Reference & \\
\hline Using cocaine/crack & 15.73 & $1.82-136.13$ & 0.012 & 0.09 & $0.03-2.54$ & 0.156 \\
\hline \multicolumn{7}{|l|}{ Use of heroin } \\
\hline Not using heroin & 1.00 & Reference & & 1.00 & Reference & \\
\hline Using heroin & 32.06 & $7.31-140.61$ & $<0.001$ & 19.48 & $2.29-166$ & 0.007 \\
\hline \multicolumn{7}{|l|}{ Use of diazepam } \\
\hline Not using diazepam & 1.00 & Reference & & 1.00 & Reference & \\
\hline Using diazepam & 10.93 & $2.95-40.46$ & $<0.001$ & 3.89 & $0.66-22.97$ & 0.134 \\
\hline AUROC $(95 \%$ CI) & & & & $88.17 \%$ & $84.53-91.8$ & \\
\hline AIC & & & & & 331.44 & \\
\hline
\end{tabular}

AIC Akaike information criterion, $A U R O C$ area under the receiver operating characteristic curve, $C I$ confidence interval, $O R$ odds ratio against the development of drug and substance misuse [27-29].

As indicated by participants during the FGD, lack of parental care for an individual may lead to wayward behavior. Effective communication between adolescents and their parents/guardians is very necessary for effective supervision to prevent the abuse of drugs. The family is supposed to be a warm welcoming part of human life. In situations where there are conflicts at home or amongst family members, it has a negative impact on the emotional, psychological, and social development of a person. Studies have identified family instability as a major cause of substance abuse amongst teenagers [30].

Participants with family members who abused drugs were two times more likely to abuse tramadol than were participants whose family members were not drug abusers. Jacobs et al. [31] reported that having family members who drank alcohol increased the likelihood that the adolescent would consume alcohol. Other authors have tried to link this observation to genetic inheritance [9].

Peer influence is also known to be a major factor in behavior development. Our results indicated that participants who had friends who abused drugs when they were growing up had higher odds of abusing tramadol than participants who did not have such friends. Conformity in order to belong has often been a reason for peer influence.
Some drivers and assistants in the current study abused tramadol because some of their colleagues did so and recommended it to be effective in reducing occupational pain. A qualitative study by Tam and Foo [9] also identified peer influence as one of the key determinants in the abuse of drugs.

Abuse of a substance has often been associated with increased odds of abusing other substances. Our findings indicate that participants who consumed alcohol had higher odds of abusing tramadol than those who did not. This is worrying because tramadol interacts with alcohol, which could produce an increased effect leading to alcohol intoxication. This interaction may reduce cognitive function, increase intracranial pressure, and induce eccentric behavior, which can lead to road accidents and other harmful effects [26].

Our results also revealed that drivers and assistants who used tobacco were three times more likely to abuse tramadol than were those who did not. Shalaby et al. [32] revealed a bidirectional increased dependence when tobacco and tramadol were taken concurrently.

Drivers and assistants who abused marijuana were four times more likely to abuse tramadol than those who did not. The pharmacologic effects sought by most users of cannabis products are sedation, mental relaxation, euphoria, and a mild hallucinogenic effect. Since tramadol and marijuana 
act on the central nervous system, there is a major likelihood of plausible interactions that can lead to harmful effects [2].

Tramadol is generally considered to have a very low risk of dependence and abuse, but rare cases of tramadol dependence have been described in patients without prior substance abuse history [2]. Of those who abuse tramadol, $49 \%$ are likely to be dependent on the drug. This finding is consistent with a report by Mohamed et al. [33], who found nearly onehalf $(49 \%)$ of substance abusers in an outpatient addiction clinic in Egypt were highly dependent on tramadol. This calls for stakeholders' attention because dependency on tramadol has dire consequences for the general productivity of the nation.

Our study had some limitations. These include the fact that no sampling frame was available to allow for all the commercial drivers and assistants to have an equal chance of being selected for participation in the study. Some of those sampled also could not participate because it was their turn to load passengers. Similarly, the number of vehicles or drivers and assistants per transport terminal was not known, so the number of respondents per terminal may not be representative of the terminal as some terminals may be over represented and others under represented. Also, the number of terminals per submetropolis may not be representative of the area. The number of FGDs was not enough to reach saturation as this was only an exploratory way to document the views of some drivers and assistants to inform an expanded study. These limitations notwithstanding, this study has established that the level of tramadol abuse and dependence is high among commercial drivers and assistants in the AMA of Ghana. We also identified some socioenvironmental factors associated with tramadol abuse. Addressing these could help reduce the incidence of tramadol abuse given the comprehensive methodology employed and the appreciable number of people recruited to take part in the study.

\section{Conclusion and Recommendations}

The prevalence of tramadol abuse among commercial drivers and assistants in the AMA was $24.9 \%$, with $49.1 \%$ of abusers being dependent on it. Parental supervision and the home environment during adolescence, peer influence, and history of abuse of other substances were significantly associated with tramadol abuse. We recommend additional qualitative study to understand the main reasons behind dependence on tramadol as this could be contributing to road traffic accidents in Ghana and other countries in the subregion. This will also enable the authorities, including the Ghana Road Safety Commission, the Police Service, and the Ghana Health Service to develop interventional programs to reduce the incidence of tramadol abuse.
Acknowledgements This research was financially supported by the FDA, Ghana. The authors are grateful to the management and staff for their immense support in the course of this research work. Many thanks also go to all the study participants and the management of the study site for their permission. We are also grateful to all the research assistants for their help in the data collection.

\section{Declarations}

Funding No external funding was received for this work.

Conflicts of interest Mavis Danso and Francis Anto have no conflicts of interest that are directly relevant to the content of this article.

Ethical approval Ethical clearance for the study was obtained from the Ghana Health Service Ethics Review Committee (No: GHSERC026/02/19) before commencement of the work. Permission was also obtained from the AMA and the managers of the various transport terminals from which participants were recruited. Written informed consent was obtained from all study participants before enrolment into the study. Participants who were found to have moderate risk for dependence on tramadol were given counseling and educated on how they could stop using the drug. Those found to be at high risk of dependence were referred to the Addictive Disease Unit of the Korle $\mathrm{Bu}$ Teaching Hospital for further diagnosis and management.

Consent to participate All participants were aged $\geq 18$ years and provided written informed consent before enrolment into the study.

Consent for publication Not applicable.

Availability of data and material All data generated during the study are included in the published work.

Code availability Not applicable.

Authors' contributions Conceptualization: MD, FA. Data curation: MD. Formal analysis: MD. Funding acquisition: MD. Methodology: MD, FA. Project administration: MD. Visualization: MD, FA. Writing—original draft: MD. Writing—review and editing: FA

Open Access This article is licensed under a Creative Commons Attribution-NonCommercial 4.0 International License, which permits any non-commercial use, sharing, adaptation, distribution and reproduction in any medium or format, as long as you give appropriate credit to the original author(s) and the source, provide a link to the Creative Commons licence, and indicate if changes were made. The images or other third party material in this article are included in the article's Creative Commons licence, unless indicated otherwise in a credit line to the material. If material is not included in the article's Creative Commons licence and your intended use is not permitted by statutory regulation or exceeds the permitted use, you will need to obtain permission directly from the copyright holder. To view a copy of this licence, visit http://creativecommons.org/licenses/by-nc/4.0/.

\section{References}

1. UNODC. World Drug Report. United Nations Publications, Sales No. E.18.X1.9. 2018. https://www.unodc.org/wdr2018.

2. WHO. Tramadol update review report Agenda item 6.1 Expert Committee on Drug Dependence Thirty-sixth Meeting; Geneva: 
World Health Organization. 2014. http://www.who.int/medicines/ areas/quality_safety/6_1_Update.pdf.

3. Cooper AJM, Willis J, Fuller J, Benecke H, Leighton-Scott J, Andersohn F, Kim J, Maier C, Knaggs RD. Prevalence and incidence trends for diagnosed prescription opioid use disorders in the United Kingdom. Pain Ther. 2017;6:73-84. https://doi.org/ 10.1007/s40122-017-0070-9.

4. Chen S, Argáez C. Tramadol for the management of pain in adult patients: a review of clinical effectiveness-an update. Canadian Agency for Drugs and Technologies in Health, Ottawa (ON). 2018. https://www.ncbi.nlm.nih.gov/books/NBK538277/. Accessed 10 Mar 2021.

5. Hallam C. Tramadol: Three cheers for the Expert Committee on Drug Dependence. 2019. https://idpc.net/blog/2019/02/trama dol-three-cheers-for-the-expert-committee-on-drug-dependence. Accessed 20 Mar 2021.

6. Lara-Solares A, Olea MA, Pinos ALAB, Cohén SB, Sierra PB, Juárez ERD, Escudero OASE, Escudero JGS, Cantisani JAF. Latin-American guidelines for cancer pain management. Pain Manag. 2017;7:287-98. https://doi.org/10.2217/pmt-2017-0006 (Accessed 20 Mar 2021).

7. Fynn A, Helberg E, Godman B, Meyer JC. Drug utilization review of tramadol hydrochloride in a regional hospital in South Africa; findings and implications. Hosp Pract. 2020. https://doi.org/10. 1080/21548331.2020.1724454 (Accessed 20 Mar 2021).

8. INCB. Report of the International Narcotics Control Board for 2016. www.incb.org.

9. Tam CL, Foo YC. Contributory factors of drug abuse and the accessibility of drugs. Int J Collab Res Intern Med Public Health. 2012. http://internalmedicine.imedpub.com/contributory-factorsof-drug-abuse-and-the-accessibilityof-drugs.pdf

10. Ryan NM, Isbister GK. Tramadol overdose causes seizures and respiratory depression but serotonin toxicity appears unlikely. Clin Toxicol. 2015;53:545-50. https://doi.org/10.3109/15563 650.2015.1036279.

11. Nakhaee S, Amirabadizadeh A, Brent J, Moghaddam EM, Foadoddini M, Farrokhfall K, Hosseini M, Abdollahi M, Mehrpour O. Tramadol and the occurrence of seizures: a systematic review and metaanalysis. Crit Rev Toxicol. 2020. https://doi.org/10.1080/ 10408444.2019.169486 (Accessed 20 Mar 2021).

12. Habibollahi P, Garjani A, Vahdati SS, Sadat-Ebrahimi S-R, Parnianfard N. Severe adverse effects associated with tramadol over dose in 2013-2017, Iran. Epidemiol Health. 2019. https://doi.org/ 10.4178/epih.e2019026 (Accessed 20 Mar 2021).

13. Sansone RA, Sansone LA. Tramadol: seizures, serotonin syndrome, and co-administered antidepressants. Psychiatry. 2009; 6(4): 17-21. https://europepmc.org/article/PMC/2714818. Accessed 10 Mar 2021.

14. National Road Safety Commission. Road Traffic Crash Statistics 2016. http://www.nrsc.gov.gh/images/statistics/Road-traffic-crashstatistics-2016.pdf

15. Coleman A. Road traffic accidents in Ghana: a public health concern, and a call for action in Ghana, (and the sub-region). Open J Prev Med. 2014;04:822-8. https://doi.org/10.4236/ojpm.2014. 411092.

16. Kuypers KPC, Legrand SA, Ramaekers JG, Verstraete AG. A case-control study estimating accident risk for alcohol, medicines and illegal drugs. PLoS ONE. 2012;7(8):e43496. https://doi.org/ 10.1371/journal.pone.0043496.

17. Orriols L, Delorme B, Gadegbeku B, Tricotel A, Contrand B, CESIR research group, et al. Prescription medicines and the risk of road traffic crashes: a French registry-based study. PLoS Med. 2010;7:e1000366. https://doi.org/10.1371/journal.pmed.1000366.
18. Gilson AM, Kreis PG. The burden of the nonmedical use of prescription opioid analgesics. Pain Med. 2009;10:S89-100. https:// doi.org/10.1111/j.1526-4637.2009.00668.x.

19. Ghana Demographic and Health survey, 2014 Report. http:// www2.statsghana.gov.gh/docfiles/publications/2014\%20GDHS\% 20\%20Report.pdf

20. Cochran WG. Sampling techniques. 3rd ed. New York: Wiley; 1977.

21. Hartung C, Lerer A, Anokwa Y, Tseng C, Brunette W, Borriello G. 2010. http://www.nixdell.com/classes/Tech-for-the-under served/Hartung.pdf

22. WHO. A s s i s t The Alcohol, Smoking and Substance Involvement Screening Test (ASSIST) manual for use in primary care; Geneva: World Health Organization. 2010. www.who.int/subst ance_abuse.

23. Braun V, Clarke V. Successful qualitative research a practical guide for beginners. 2013. https://core.ac.uk/download/pdf/16706 435.pdf. Accessed 25 June 2019.

24. Lofwall MR, Babalonis S, Nuzzo PA, Siegel A, Campbell C, Walsh SL. Efficacy of extended-release tramadol for treatment of prescription opioid withdrawal: a two-phase randomized controlled trial. Drug Alcohol Depend. 2013;133:188-97. https://doi. org/10.1016/J.DRUGALCDEP.2013.05.010.

25. Subedi M, Bajaj S, Kumar MS, Mayur YC. An overview of tramadol and its usage in pain management and future perspective. Biomed Pharmacother. 2019;111:443-51. https://doi.org/10. 1016/J.BIOPHA.2018.12.085.

26. Bashirian S, Barati M, Fathi Y. Prevalence and factors associated with tramadol abuse among college students in West of Iran: an application of the theory of planned behavior. Avicenna J Neuropsychol Physiol. 2014. https://doi.org/10.17795/ajnpp-20314.

27. Olsson MO, Öjehagen A, Brådvik L, Kronstrand R, Håkansson A. High rates of tramadol use among treatment-seeking adolescents in Malmö, Sweden: a study of hair analysis of nonmedical prescription opioid use. J Addict. 2017. https://doi.org/10.1155/ 2017/6716929.

28. Yunusa U, Lawal BU, Idris M, Muhammad HM, Adamu D. Determinants of substance abuse among commercial bus drivers in Kano Metropolis. Am J Nurs Sci. 2017;6:125-30. https://doi. org/10.11648/j.ajns.20170602.16.

29. Green KM, Doherty EE, Fothergill KE, Ensminger ME. Marriage trajectories and health risk behaviors throughout adulthood among urban African Americans. J Fam Issues. 2012;33:1595-618. https://doi.org/10.1177/0192513X11432429.

30. Rabeea IH. Risk factors of drugs dependence among people in Gaza Strip. 2013. https://iugspace.iugaza.edu.ps/handle/20.500. 12358/21206.

31. Jacobs W, Barry AE, Xu L, Valente TW. Hispanic/Latino adolescents' alcohol use: influence of family structure, perceived peer norms, and family members' alcohol use. Am J Health Educ. 2016;47:253-61. https://doi.org/10.1080/19325037.2016.11791 41.

32. Shalaby AS, Sweilum OAEH, Ads MK. Does tramadol increase the severity of nicotine dependence? A study in an Egyptian sample. J Psychoact Drugs. 2015;47(3):197-202. https://doi.org/10. 1080/02791072.2015.1050534.

33. Mohamed N, El Hamrawy L, Shalaby A, El Bahy M, Abd AM. An epidemiological study of tramadol $\mathrm{HCl}$ dependence in an outpatient addiction clinic at Heliopolis Psychiatric Hospital. Menoufia Med J. 2016;28:591. https://doi.org/10.4103/1110-2098.163924. 